\title{
FINANCIAMENTO ÀS EXPORTAÇÕES: UMA AVALIAÇÃO DOS IMPACTOS DOS PROGRAMAS PÚBLICOS BRASILEIROS ${ }^{(*)}$
}

\author{
Jefferson Galetti ${ }^{a}$ \\ Celio Hiratuka ${ }^{b}$
}

RESUMO: O artigo procura avaliar qual o impacto dos programas públicos de financiamento às exportações existentes no Brasil. Especificamente o artigo analisa os resultados do PROEX e do BNDES-EXIM. Para cumprir o objetivo o trabalho utiliza a metodologia de propensity score matching combinada com análise de painel. Os resultados apontam que os programas públicos brasileiros, em especial o BNDES-EXIM, tem impacto positivo sobre o valor exportado das firmas apoiadas.

PALAVRAS-CHAVE: Exportações; financiamento às exportações; PROEX; BNDES.

CLASSIFICAÇÃO JEL: F13; F14.

* Artigo recebido em 21/07/2011 e aprovado em 22/10/2013.

a Mestre em Economia pela Universidade Estadual de Campinas (UNICAMP) e economista do Departamento de Pesquisas e Estudos Econômicos da Federação das Indústrias do Estado de São Paulo (FIESP). Contato: jeffersongaletti@yahoo.com.br.

b Doutor em Economia pela UNICAMP e professor do Instituto de Economia da mesma instituição. Contato: celio@eco.unicamp.br 


\title{
EXPORT FINANCING: A REVIEW ON THE IMPACTS OF BRAZILIAN PUBLIC PROGRAMS
}

\begin{abstract}
The aim of this paper is to assess the impact of public programs of exports financing in Brazil. Specifically, the paper analyses the results of PROEX and BNDES-EXIM. To achieve that objective, a propensity score matching, combined with panel data analysis was used. The results show that Brazilian government programs to finance exports, specially the BNDES-EXIM has a positive impact on the export value of supported firms.
\end{abstract}

KEYWORDS: Exports; export financing; PROEX; BNDES. 


\section{INTRODUÇÃO}

Apesar do expressivo crescimento das exportações brasileiras nas duas últimas décadas, em especial a partir de 2003, quando passaram a aproveitar o cenário de forte crescimento da economia mundial, a inserção brasileira no comércio exterior apresenta algumas características que exigem atenção por parte dos exportadores e dos formuladores de política comercial.

As exportações cresceram em média, 5,8\% ao ano entre 1991 e 2002 e a 22,0\% entre 2003 e 2008. Embora o ritmo de crescimento tenha sofrido uma interrupção em 2009, devido à eclosão da crise financeira global, as exportações voltaram a crescer em 2010 (32\% em relação a 2009).

Apesar do desempenho favorável das exportações no período em termos quantitativos, em termos qualitativos não se observaram mudanças na composição da pauta em direção a produtos industriais de maior sofisticação e complexidade tecnológica. Entre 1991 e 2002 a participação média anual dos produtos manufaturados nas exportações foi de 56,9\% e entre 2003 e 2009 esse percentual diminuiu para 51,8\%.

A forte demanda pelas commodities agrícolas e minerais, a melhora dos termos de intercâmbio e as estratégias das empresas do setor para incrementar a competitividade externa foram fundamentais para essa dinâmica. Os produtos industriais, por sua vez, encontram muitas dificuldades para manter sua competitividade internacional, em virtude especialmente da persistente trajetória de apreciação cambial, além da concorrência acirrada protagonizada pelo surgimento e consolidação da China como grande exportadora de produtos manufaturados. O cenário pós-crise financeira aponta para uma conjuntura de acirramento ainda maior na concorrência internacional por esses produtos, em especial porque a demanda dos países centrais ainda deve continuar com crescimento lento por um período relativamente longo.

Diante desse quadro, as políticas comerciais de maneira geral, e em particular as políticas de financiamento à exportação adquirem um papel estratégico, principalmente para os produtos mais prejudicados com a taxa de câmbio desfavorável e com o reduzido dinamismo da demanda global, em especial dos países desenvolvidos.

O objetivo deste artigo é avaliar os efeitos dos programas públicos de financiamento às exportações existentes no Brasil sobre o valor exportado das firmas apoiadas e em que medida esses programas tem atingido seus objetivos. Para isso, recorreu-se ao método de propensity score matching combinado com análise de painel, de maneira a avaliar os impactos dos programas de financiamento a partir da comparação dos resultados das firmas apoiadas com um grupo de controle adequado composto por empresas não apoiadas.

Este artigo tem mais três itens, além desta introdução. $\mathrm{O}$ primeiro trata das características gerais dos mecanismos de financiamento às exportações e das principais mo- 
dalidades existentes no Brasil. O segundo apresenta uma análise dos programas públicos de financiamento à exportação, de modo a identificar a especialização setorial dos programas, além do modelo econométrico utilizado para estimar os efeitos desses programas sobre o valor exportado pelas empresas industriais brasileiras. $\mathrm{O}$ último item traz as conclusões e as considerações finais.

\section{FINANCIAMENTO ÀS EXPORTAÇÕES NO BRASIL}

\subsection{CARACTERIZAÇÃO GERAL}

Uma política de promoção de exportação pode ser entendida como as "medidas de políticas públicas que realmente ou potencialmente incrementam a atividade exportadora na empresa, na indústria ou em nível nacional” (Seringhauss e Rosson, 1990 apud Markwald e Puga, 2002, p. 101, nota de rodapé ). Segundo os autores, “[o] papel da promoção de exportações é a criação da consciência da exportação como opção de crescimento e expansão do mercado; a redução ou remoção das barreiras à exportação e a criação de incentivos e de várias formas de assistência aos potenciais e atuais exportadores" (idem). Ela pode atuar em várias frentes, de forma coordenada e integrada entre si, como por exemplo, na melhoria da competitividade institucional, financeira, operacional, produtiva exportadora, comercial e negociação internacional (Pianto e Chang, 2006).

A análise das ações destinadas à competitividade financeira compreende o objeto principal deste artigo, e envolve basicamente as linhas de financiamento público à exportação. Vale lembrar que a política pública destinada a melhorar a competitividade financeira das exportações compreende também a concessão de seguros à exportação e fundos de aval para a concessão de garantias aos exportadores, embora estes instrumentos não estejam contemplados no presente estudo.

No caso específico do sistema brasileiro, o principal instrumento de financiamento à exportação utilizado é o Adiantamento de Contrato de Câmbio (ACC), linha privada que consiste na antecipação do pagamento, parcial ou total, em moeda nacional do valor em moeda estrangeira do contrato de exportação firmado entre a empresa exportadora nacional e o importador estrangeiro (Veiga e Iglesias, 2000; Blumenschein e Leon, 2002).

Essa operação é realizada por bancos credenciados que antecipam o valor a ser recebido pelo agente exportador em até 360 dias. No final desse prazo, pode haver o refinanciamento da operação por mais 210 dias por meio do Adiantamento de Cambiais Entregues (ACE), desde que o embarque da mercadoria tenha sido efetuado. Portanto, os instrumentos privados abrangem as etapas pré- e pós-embarque e tem prazo máximo de 570 dias. 
A provisão de fundos para as operações de ACC origina-se de fontes externas e o custo de operação para os exportadores é composto pela taxa de captação dos bancos - baseada na London Interbank Offered Rate (Libor) - acrescida do spread do agente financeiro e do spread de risco. A remuneração que o agente financeiro cobrará de seu cliente no país depende de variáveis de gestão de risco e produto, como o seu relacionamento com o cliente, o porte e a higidez financeira deste, enquanto que o spread de risco depende da liquidez internacional, do apetite por risco dos investidores internacionais e do ambiente macroeconômico do país receptor - usualmente medido pelo chamado "risco-país" (Pereira e Maciente, 2000; Veiga e Iglesias, 2000).

Nos últimos anos, o ACC vem perdendo espaço para o Pré-Pagamento de Exportação ou Pagamento Antecipado, que se aproveitou da maior liberalização dos fluxos de capital após 1995. Nesse instrumento, os recursos são obtidos de bancos estrangeiros e os bancos nacionais trabalham como intermediários, e por essa razão não é considerado um instrumento de crédito bancário doméstico. A oferta depende das condições de liquidez internacional e do índice de risco-país.

Embora importantes, os mecanismo privados de financiamento obedecem a critérios gerais de relacionamento entre o banco e o cliente, como, por exemplo, a análise de risco, a capacidade de solvência, oferta de garantias pelas empresas e seu histórico financeiro. Muitas vezes, os critérios de desempenho exportador da empresa não são levados em consideração. As variáveis tamanho e reputação são determinantes para a percepção do risco e condicionam em grande medida a liberação de recursos para as empresas exportadoras. Em decorrência, as empresas de menor porte podem não possuir acesso adequado aos mecanismos de financiamento à exportação, nem conseguir se manter em igualdade com os concorrentes estrangeiros, perdendo oportunidades para exportar. Essa exclusão pode gerar enormes perdas - privadas e sociais - na forma de transações não realizadas, rendas e empregos não criados (Rhee, 1989; Veiga e Iglesias, 2000).

Por sua vez, a existência de linhas de financiamento público para exportações, como complemento às linhas privadas pode se justificar pelas diferenças existentes entre os diversos setores e produtos em termos de complexidade e sofisticação tecnológica do processo de produção, duração do ciclo de desenvolvimento, produção e comercialização. Setores com ciclos mais longos e processos mais complexos poderiam ser prejudicados com a avaliação somente pela ótica privada. Além disso, a existência de maiores externalidades relacionadas às atividades mais intensivas em tecnologia e $\mathrm{P} \& \mathrm{D}$ poderia justificar as linhas de financiamento público às exportações de produtos mais intensivos em tecnologia.

As linhas públicas de financiamento à exportação são o BNDES Exim do Banco Nacional do Desenvolvimento Econômico Social (BNDES) e o Programa de Financia- 
mento às Exportações (Proex) do Banco do Brasil. O programa de financiamento à exportação do BNDES foi criado em 1991, com o nome de Finamex, e era destinado apenas ao setor de bens de capital. A partir de 1996 o programa passou por mudanças que incluíram outros setores, nas modalidades de financiamento pré e pós-embarque. Passaram a receber financiamento os produtos químicos, têxteis, eletrônicos, calçados, couros e alimentos, além dos serviços de engenharia.

Os recursos vem de fundos diversos, tais como o Fundo de Amparo ao Trabalhador (FAT) e linhas externas, inclusive de organismos multilaterais. Um dos objetivos da linha de financiamento à exportação do BNDES é ampliar a participação dos produtos de maior geração de valor no comércio exterior brasileiro (Catermol, 2005).

As condições do financiamento pré-embarque do BNDES Exim variam de acordo com o setor, com o porte da empresa, com o tipo de produto, entre outras características. Destina-se aos bens com índice de nacionalização mínimo de $60 \%$ em valor, com o prazo de até 36 meses, de acordo com as mercadorias financiadas. O pagamento pode ser realizado em parcela única no final do período ou em até 24 parcelas a contar retroativamente da data limite. O custo do financiamento é composto pela taxa de juros acrescida às remunerações do BNDES e da instituição financeira credenciada. Para as micro, pequenas e médias empresas são oferecidos recursos à Taxa de Juros de Longo Prazo (TJLP) ou Libor semestral acrescida da variação cambial do dólar americano. Para as grandes empresas e máquinas industriais classificados no Grupo $\mathrm{I}^{1}$ dos bens elegíveis é oferecido a TJLP ou Libor semestral mais variação cambial, e para as demais operações das grandes empresas para os itens restantes do Grupo I, Grupo II e III é oferecido TJLP mais 1\% a.a. ou Taxa de Juros Fixa Pré-embarque (TJFPE) (Moreira e Panariello, 2009).

O financiamento à comercialização dos produtos - Exim Pós-Embarque - é realizado após o embarque das mercadorias e divide-se em duas modalidades - crédito concedido diretamente ao exportador (supplier credit) ou ao importador (buyer credit). Esse tipo de apoio à exportação permite ao exportador financiar seu cliente em condições de igualdade com a concorrência externa ao oferecer prazos de pagamento vigentes no mercado internacional, e ao mesmo tempo receber o valor da importação antecipadamente.

O supplier credit consiste no refinanciamento ao exportador. Este apresenta ao BNDES os títulos ou documentos de venda a prazo que concedeu ao seu cliente (importador) e recebe o resultado da operação de desconto dos títulos pelo BNDES. Por

\footnotetext{
Essencialmente o Grupo I abrange os bens de capital; o Grupo II é composto em sua maioria por bens de consumo e bens intermediários, enquanto o Grupo III contém os automóveis de passeio, armamentos e alguns produtos químicos (Catermol, 2005).
} 
sua vez, o financiamento do tipo buyer credit depende do estabelecimento de contratos em que estejam envolvidos a empresa importadora - com a interveniência do exportador - e o BNDES. O custo e o prazo de análise dos projetos dessa modalidade são maiores, refletindo o custo da coleta de informações referentes à contraparte localizada no exterior.

A participação do BNDES pode chegar até a $100 \%$ do valor exportado e pode se estender a até 12 anos. $\mathrm{O}$ custo financeiro consiste na cobrança da taxa de juros internacional (Libor) acrescida da remuneração do BNDES e da comissão do banco mandatário. Esta última é devida pela empresa beneficiária em virtude dos serviços prestados pelo banco, que incluem a análise da documentação, o repasse de recursos à beneficiária, cobrança, fechamento de câmbio e liquidação da operação.

O prazo total do financiamento varia significativamente com o tipo de bem exportado ou o tipo de projeto a que ele se destina. $\mathrm{O}$ apoio às exportações de máquinas normalmente apresenta prazos mais curtos, entre dois e cinco anos, enquanto que os bens e serviços destinados a grandes obras de infraestrutura contam com prazos maiores.

A Tabela 1 apresenta os valores desembolsados pelo BNDES Exim entre os anos de 2000 a 2009, divididos pela modalidade Pré e Pós-Embarque. Já no Gráfico 1 aparecem os valores desembolsados pelo BNDES Exim e pelo Proex até 2008.

Tabela 1 - Desembolsos do BNDES Exim no período 2000-2009 (em US\$ milhões)

\begin{tabular}{c|c|c|c}
\hline Ano & Linhas pré-Embarque & Linhas Pós-Embarque & Total \\
\hline 2000 & 1.304 & 1.779 & 3.083 \\
\hline 2001 & 970 & 1.633 & 2.603 \\
\hline 2002 & 1.278 & 2.670 & 3.948 \\
\hline 2003 & 1.981 & 2.025 & 4.007 \\
\hline 2004 & 1.921 & 1.940 & 3.862 \\
\hline 2005 & 3.166 & 2.697 & 5.863 \\
\hline 2006 & 4.475 & 1.863 & 6.337 \\
\hline 2007 & 3.493 & 698 & 4.191 \\
\hline 2008 & 4.903 & 1.694 & 6.597 \\
\hline 2009 & 6.180 & 2.150 & 8.330 \\
\hline
\end{tabular}

Fonte: Elaboração própria com base em dados do BNDES.

No triênio 2007-2009, o BNDES desembolsou US\$19,1 bilhões para o financiamento à exportação. Desse total, a modalidade Pré-Embarque, que assumiu a liderança nos desembolsos a partir de 2005 , respondeu por $76,2 \%$. Na classificação por categoria de uso, os Bens de Capital receberam 77,1\% do volume de recursos dessa modalidade. Os Bens de Consumo e Intermediários ficaram com 21\% e os Serviços com apenas $1,9 \%$. 


\section{Gráfico 1 - Desembolsos dos programas públicos de financiamento à exportação (em US\$ milhões)}

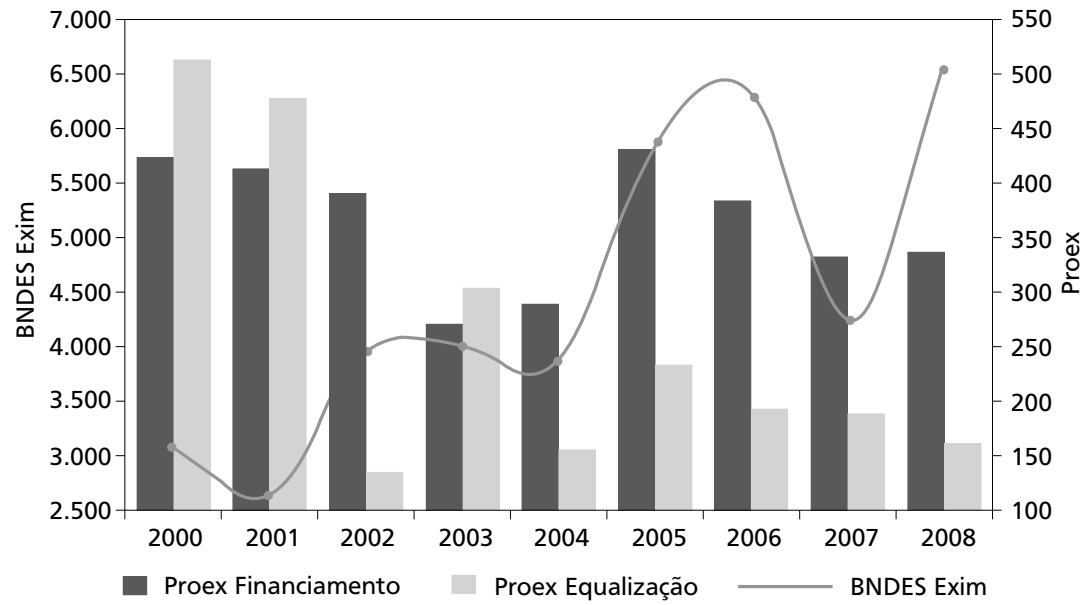

Fonte: Elaboração própria com base em dados da Secretaria de Comércio Exterior do Ministério de Desenvolvimento, Indústria e Comércio (SECEX/MDIC).

O financiamento à comercialização - Pós-Embarque - representou 23,8\% dos desembolsos do triênio. Nesta modalidade, a maior parcela dos recursos destinou-se aos setores de Serviços. Aproximadamente $62 \%$ dos valores desembolsados foram para essa categoria, enquanto os Bens de Capital responderam pelo restante.

O Proex foi criado em 1991 pela Lei no 8.187 e é gerido pelo Banco do Brasil com os recursos disponibilizados anualmente no Orçamento da União. Seu objetivo é dotar os exportadores brasileiros com condições similares às dos concorrentes internacionais. Divide-se em duas modalidades, o Proex Financiamento e o Proex Equalização de taxas de juros. O MDIC relaciona os produtos aptos a receber o financiamento, que compreendem bens, serviços associados à venda e assistência técnica de máquinas e equipamentos, softwares e filmes (Moreira e Santos, 2001).

Esse programa apresenta algumas limitações, como por exemplo, a incerteza em relação à continuidade dos fluxos de recursos decorrente de seu funding ser decidido anualmente de acordo com a disponibilidade de recursos do Orçamento Geral da União. A variação da taxa de câmbio também influencia esse programa, pois os recursos são disponibilizados em moeda nacional. Nesse caso, o sentido da variação cambial atua com efeitos distintos em relação às exportações e seu financiamento: uma apreciação da moeda nacional resulta na disponibilidade de um montante maior para o financiamento ao mesmo tempo em que torna as exportações brasileiras menos atrativas para os importadores internacionais. 
O Proex Financiamento é destinado à etapa pós-embarque (comercialização) das transações de comércio exterior e pode ser concedido diretamente ao exportador (supplier credit) ou ao importador (buyer credit). No caso em que os recursos são liberados para o exportador, a operação ocorre por meio de desconto de títulos representativos da venda externa, realizado após o embarque das mercadorias ou do faturamento dos serviços. Já as operações efetivadas na modalidade buyer credit dependem da contratação direta do financiamento entre o governo brasileiro e as entidades estrangeiras envolvidas na transação. O importador deve acusar o recebimento das mercadorias ou dos serviços prestados e autorizar a liberação dos recursos para a empresa exportadora.

Em 2002, a Câmara de Comércio Exterior (Camex) estabeleceu mudanças nas diretrizes do programa com o objetivo de destinar os recursos para as micro, pequenas e médias empresas com faturamento bruto anual de até R\$ 600 milhões (Moreira e Panariello, 2009). O montante dos recursos liberados por essa modalidade pode cobrir até $100 \%$ do valor exportado quando o prazo do financiamento não ultrapassar dois anos e até $85 \%$ do valor para os demais casos com o custo financeiro baseado na taxa de juros do mercado internacional. O prazo desse programa varia de 60 dias a dez anos.

Já o Proex Equalização destina-se a equalizar as taxas de juros, ou seja, cobrir a diferença entre a taxa de juros incidente sobre o financiamento de uma empresa brasileira e a taxa de juros praticada no mercado internacional, com o intuito de igualar as condições dos exportadores domésticos frente aos concorrentes externos (Moreira e Panariello, 2009). O Tesouro Nacional assume o pagamento de parte dos encargos financeiros, mas deixa para o mercado a função de prover fundos para a operação de financiamento à exportação. Cabe ao exportador negociar livremente com o financiador os termos sobre as garantias, a taxa de juros, o prazo de financiamento e o percentual a ser financiado (Moreira e Santos, 2001). O prazo de equalização pode chegar a dez anos - com o mínimo de 60 dias - dependendo do valor da mercadoria ou da complexidade dos serviços prestados. A margem de equalização sofreu modificações ao longo do tempo e desde 1998 é definida como a margem suficiente para tornar os encargos financeiros compatíveis com os do mercado internacional (Moreira e Panariello, 2009).

\subsection{ANÁLISE PRELIMINAR DOS MECANISMOS PÚBLICOS DE FINANCIAMENTO À EXPORTAÇÃO}

Os desembolsos dos mecanismos de financiamento à exportação (públicos e privados) no Brasil cresceram de forma acentuada no período 2000-2008, à taxa anual de 10,2\%. No entanto, esse crescimento foi inferior à expansão das vendas externas brasileiras (15,3\% a.a.), o que reduziu a participação das linhas de financiamento no total exportado. Em 2000 o total financiado pelos programas públicos e linhas privadas representava $75,4 \%$ das exportações enquanto que em 2008 a participação reduzira-se a 50,1\%. 
Os mecanismos privados de financiamento - ACC/ACE e o Pré-Pagamento - foram responsáveis por quase $93 \%$ dos recursos destinados às empresas exportadoras e $46,5 \%$ do valor total das exportações em 2008. Esse padrão de distribuição se manteve o mesmo desde o início dos anos 1990, conforme pode ser observado no Gráfico 2.

\section{Gráfico 2 - Linhas de financiamento à exportação (em participação percentual)}

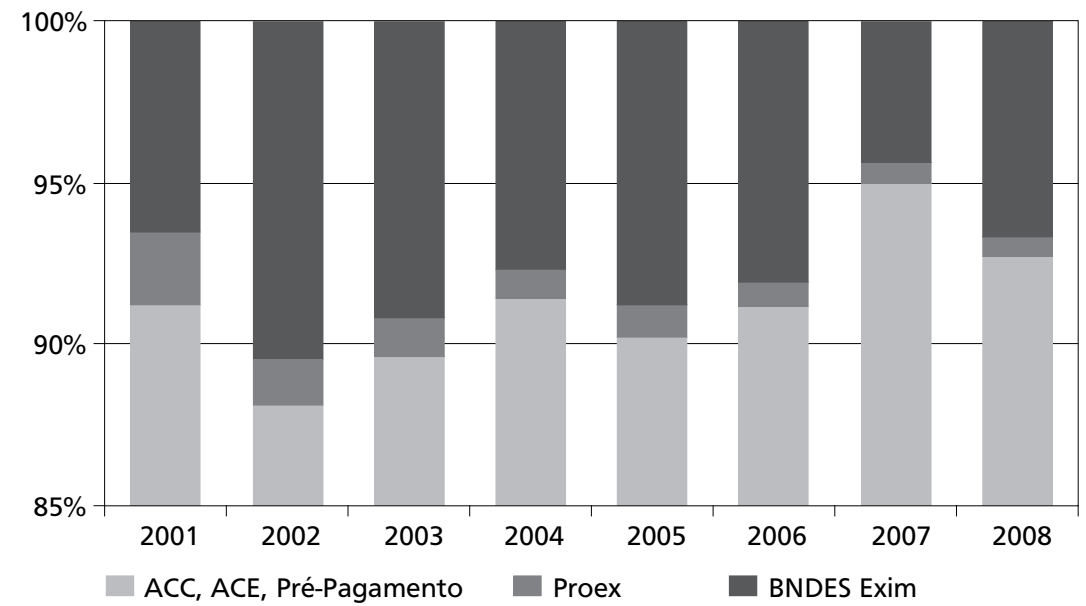

Fonte: Elaboração própria com base em dados de Moreira, Tomich e Rodrigues (2006) e Cecon (2009).

A participação dos mecanismos privados é de fundamental importância para o pleno funcionamento de um sistema de apoio à exportação. A disponibilidade de oferta de crédito pelo setor privado abre espaço para a atuação complementar dos programas públicos de financiamento à exportação. Além dos prazos destes últimos serem mais extensos, os recursos são direcionados de acordo com objetivos estratégicos, como os mostrados a seguir.

Um dos objetivos mais amplamente anunciados por ambos os programas é o de atender as exportações de setores de maior criação de valor. Por essa razão, a análise dos mecanismos públicos de financiamento à exportação irá se concentrar nos setores que compõem a classificação CNAE 1.0 da Indústria de Transformação².

2 A seção D - Indústria de Transformação inclui os produtos industrializados compostos pelos bens manufaturados e semimanufaturados. Além disso, utilizando os dados agrupados por empresas industriais, várias atividades extrativas da divisão 11 - Extração de Petróleo e serviços relacionados são transferidas para a divisão 23 - Fabricação de Coque, refino de petróleo, elaboração de combustíveis nucleares e produção de álcool, em decorrência desta classificação se basear na atividade principal da empresa. Por isso, quando o texto se referir à Indústria de Transformação, deve ser considerada essa classificação ampla. 
As informações utilizadas neste artigo fazem parte de um banco de dados organizado pelo IPEA que reúne informações da Relação Anual de Informações Sociais (RAIS) do Ministério do Trabalho e Emprego (MTE), de Comércio Exterior da SECEX/MDIC e do BNDES 3 .

A importância do BNDES Exim torna-se visível quando são considerados os valores exportados anualmente pelas empresas que obtiveram seu apoio ${ }^{4}$. As exportações dessas empresas representaram 16,8\% das exportações totais e 22,7\% das exportações industriais ${ }^{5}$ entre os anos de 2000 e 2007.

O Proex, por sua vez, apresentou desempenho mais modesto em relação aos valores desembolsados e às exportações. Apesar da baixa participação do programa $(1,1 \%$ no total de desembolsos no período 2000-2007), as vendas externas das empresas apoiadas pelo Proex Financiamento representaram 5,2\% e 3,8\% do total das exportações industriais e totais da economia brasileira, respectivamente. Por sua vez, as exportações das empresas industriais que obtiveram apoio do Proex Equalização responderam por 10,3\% das exportações industriais para todo o período 2000 a 2007 - e 7,6\% das exportações totais.

\subsection{A ESPECIALIZAÇÃO SETORIAL DAS EMPRESAS APOIADAS PELOS PROGRAMAS PÚBLICOS}

A identificação do acesso ao crédito de apoio à exportação e sua distribuição pelos diversos setores pode indicar se esses mecanismos estão à disposição das empresas devido a alguma diretriz das políticas de desenvolvimento e/ou industrial, ou se apenas serve de apoio para as exportações dos setores que já possuem vantagem competitiva no mercado internacional.

Com o objetivo de identificar a abrangência setorial dos programas de apoio à exportação, calculou-se um indicador capaz de revelar a intensidade de apoio que determinado setor recebeu em comparação com sua participação na pauta exportadora. No numerador desse indicador aparece a participação percentual do setor no total de empréstimos do BNDES ou Proex. O denominador é composto pela participação percentual deste setor no total das exportações industriais. Indicadores com valor supe-

3 Detalhes sobre a construção do banco de dados podem ser encontrados em De Negri e Salerno (2005).

4 Por razão da disponibilidade de informações, os valores exportados pelas empresas que receberam algum tipo de apoio dos programas públicos referem-se ao total exportado por essas empresas, e não apenas às exportações efetivamente apoiadas pelos recursos desses programas.

5 A partir de agora toda referência à indústria dirá respeito à indústria de transformação, conforme a explicação apresentada na nota de rodapé 2 . 
rior à unidade sugerem que o apoio ao setor é mais do que proporcional à sua participação na pauta de exportações industriais. Os Gráficos 3 e 4 mostram os resultados para o BNDES Exim e o Proex Financiamento nos anos de 2003 e 2007.

\section{Gráfico 3 - Intensidade de apoio do BNDES Exim à indústria de transformação de acordo com setores da CNAE 1.0}

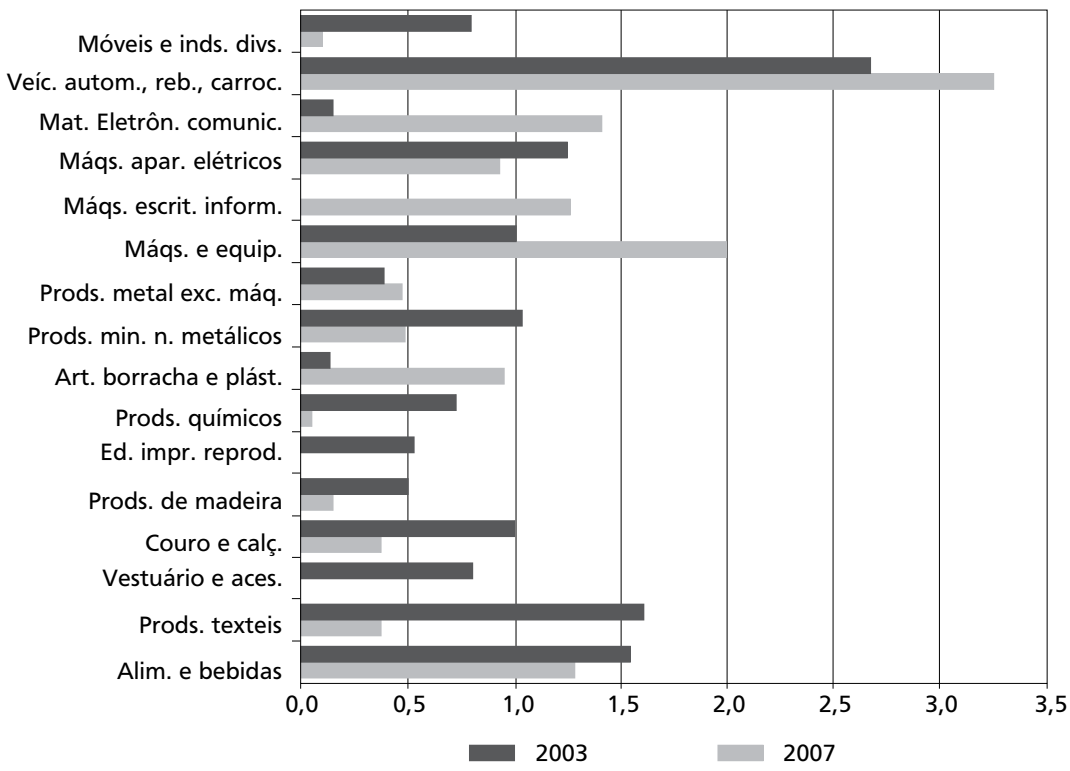

Fonte: Elaboração própria com base em dados de SECEX/MDIC e BNDES.

Os setores mais intensamente apoiados pelo BNDES Exim foram o setor de veículos automotores nos dois anos e o setor de máquinas e equipamentos em 2007. Outros setores que também se destacaram foram o de alimentos e bebidas, máquinas para escritório e equipamentos de informática e material eletrônico e equipamento de comunicação. Esses dois últimos setores aumentaram muito sua participação no período e servem para ilustrar uma característica da linha de financiamento do BNDES, seu direcionamento aos setores de maior valor agregado e maior intensidade tecnológica.

No caso do Proex Financiamento, a concentração do apoio ocorre em setores tradicionais, menos intensivos em tecnologia e que reforçam a especialização comercial brasileira. O setor de alimentos e bebidas foi o mais apoiado pelo programa em 2007, seguido pelo setor moveleiro e outras indústrias. Setores com maior valor agregado como o setor de veículos e de máquinas, aparelhos e materiais elétricos reduziram bastante sua participação em 2007. 


\section{Gráfico 4 - Intensidade de apoio do Proex Financiamento à indústria de transformação de acordo com setores da CNAE 1.0}

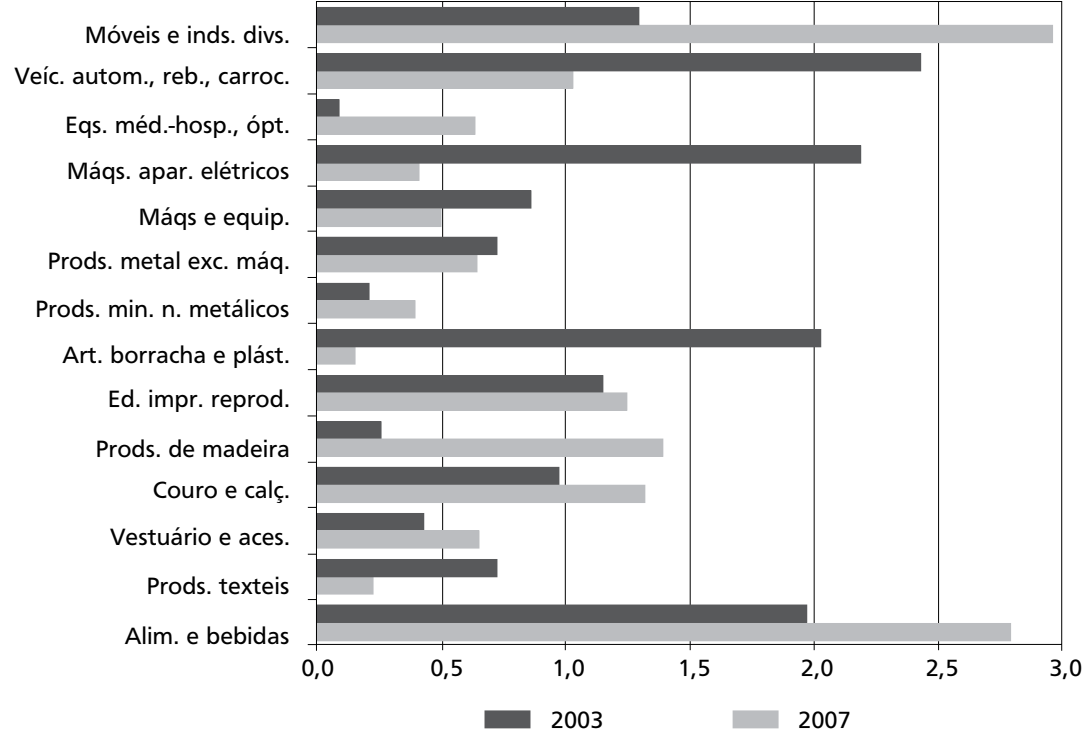

Fonte: Elaboração própria com base em dados da SECEX/MDIC.

A análise dessas informações indica que, de certa maneira, os mecanismos públicos de financiamento estão buscando complementar os mecanismos privados através de um foco direcionado, no caso do BNDES Exim, para atividades e setores com maior complexidade tecnológica, e com ciclos produtivos mais longos. No caso do Proex, em especial o Proex Financiamento, o esforço é mais dirigido em atender a demanda das empresas de menor porte, que tem dificuldades para captar recursos apenas com mecanismos privados, porém não são contemplados os setores mais intensivos em tecnologia. No entanto, pode-se afirmar que além da complementaridade entre mecanismos públicos e privados, observa-se esta característica também entre os próprios mecanismos públicos.

Entretanto, uma avaliação mais detalhada dos efeitos dos programas públicos necessita de uma metodologia que recolha informações contrafactuais de maneira mais sistematizada. Na próxima seção do artigo, busca-se avançar nessa direção.

\section{AVALIAÇÃO DOS PROGRAMAS PÚBLICOS DE FINANCIAMENTO À EXPORTAÇÃO SOBRE OS VALORES EXPORTADOS PELAS EMPRESAS INDUSTRIAIS}

\subsection{ASPECTOS METODOLÓGICOS}

A avaliação de políticas públicas é muito importante para o desenvolvimento econômico. Ela possibilita a manutenção das políticas que estejam surtindo o efeito esperado 
e também, a mudança de direção ou mesmo o abandono das políticas que não estiverem alcançando os resultados desejados.

De modo a avaliar os programas públicos de financiamento à exportação, esta seção apresenta um exercício econométrico dividido em duas etapas: na primeira, realizou-se um processo de pareamento (matching) entre as empresas industriais exportadoras com o objetivo de selecionar dois grupos de empresas com características similares exceto quanto à utilização dos recursos públicos de exportação. A etapa seguinte consistiu na estimação de um modelo de regressão utilizando dados em painel com a amostra (todas as empresas dos dois grupos) obtida anteriormente, com o intuito de identificar o efeito das políticas públicas de financiamento sobre o valor exportado de cada empresa.

A avaliação dos efeitos da política pública de financiamento à exportação baseia-se na comparação entre os valores exportados pelas empresas que receberam apoio dos programas BNDES Exim e Proex Financiamento e as exportações das empresas que não receberam o apoio desses programas no período de 2000 a 2007.

A base de dados organizada pelo IPEA permitiu a utilização de informações referentes a empresas individuais, embora estas não pudessem ser identificadas por questões de sigilo. Foram utilizados os dados de cada empresa referentes ao valor anual das exportações, às variáveis associadas à disponibilidade e qualificação de recursos humanos - a escolaridade (em anos de estudo) e a qualificação da mão de obra (proporção de trabalhadores com curso superior) - ao tamanho da empresa (em número de funcionários), à diversificação de mercados e produtos (números de países-destino e produtos exportados), além da inclusão de variáveis para controle dos setores industriais (CNAE 1.0) e unidades da federação.

Este artigo tenta estimar um resultado contrafactual, aquele que poderia ser obtido caso as empresas apoiadas não tivessem recebido o financiamento, ou seja, procura saber qual seria o nível de exportação que essas empresas apresentariam, caso não tivessem contado com o apoio dos programas públicos.

O processo de estimação é realizado da seguinte maneira: as empresas exportadoras que receberam o financiamento compõem o grupo de Tratamento enquanto as exportadoras que não receberam apoio formam o grupo de Controle. Um método de matching ou pareamento corrige o viés de seleção e forma pares entre empresas apoiadas e não apoiadas que possuem características observáveis similares. O método utilizado nesse estudo é o Propensity Score Matching (PSM), que consiste na representação do conjunto de características das empresas associado à probabilidade de acesso ao financiamento à exportação em um único escalar (Araújo, 2006).

Esse método consiste em formar pares de empresas exportadoras que estão no grupo de tratamento com empresas similares (com um escalar próximo) que com- 
põem o grupo de Controle. O PSM baseia-se na hipótese de que o tratamento (acesso aos programas públicos) é condicionado por variáveis observadas. Essas características são utilizadas para calcular a probabilidade de acesso aos recursos pelas empresas (Rosenbaum e Rubin, 1983; Cameron e Trivedi, 2006).

Considere que $\hat{p}\left(x_{j}\right)$ seja a probabilidade de a empresa $\mathrm{j}$ receber financiamento, considerando que a empresa $j$ não o recebeu. Pode-se dizer que a empresa $j$ é uma empresa com potencial para acessar os programas públicos caso exista a uma pequena distância a partir de $\hat{p}\left(x_{j}\right)$ uma empresa com $\hat{p}\left(x_{i}\right)$, considerando que a empresa $i$ exportou com apoio público. Dessa forma é realizado o pareamento entre essas duas empresas com escores de propensão muito próximos, uma retirada do grupo de Tratamento com outra do grupo de Controle.

A estimativa de $p(x)$ utilizada no pareamento foi obtida por meio de um modelo Probit que utilizou uma série de características observáveis das empresas exportadoras $^{6}$. A variável binária dependente é igual a 1 caso as empresas obtiveram apoio à exportação dos programas públicos ( $\mathrm{F}=1$ para BNDES Exim ou Proex Financiamento) ou 0 no caso das empresas exportadoras que não acessaram esses programas $(\mathrm{F}=0$ para BNDES Exim e Proex Financiamento).

Após a obtenção das estimativas de $p(x)$, foram realizadas sucessivas rodadas de pareamento com diversos graus de precisão. A primeira rodada considerou $\hat{p}(x)$ a 6 casas decimais (ex: 0,673242 ), a segunda rodada considerou $\hat{p}(x)$ a 5 casas decimais (ex: 0,67324) e assim sucessivamente, até realizar pareamentos entre empresas com $\hat{p}(x)$ a 2 casas decimais (ex: 0,67$)$. Nas rodadas de pareamento, quando uma empresa do grupo de Tratamento encontrava um par no grupo de Controle, ambas as empresas eram retiradas da amostra, ou seja, foi realizado um matching sem reposição.

Com esse procedimento, as exportações (variável de interesse) das empresas pareadas do grupo de Controle (que não receberam apoio) servem como o contrafactual das vendas externas das empresas do grupo de Tratamento (que receberam apoio), ou seja, atuam como proxy dos resultados das empresas apoiadas caso elas não tivessem recebido tal apoio.

Dentre as empresas exportadoras que receberam apoio público, a maioria delas $(85,8 \%)$ encontrou uma empresa não apoiada com características similares com a qual pode ser pareada.

\footnotetext{
6 São as variáveis já citadas anteriormente, associadas à disponibilidade e qualificação de recursos humanos (a escolaridade [em anos de estudo] e a qualificação da mão de obra [em proporção de trabalhadores com curso superior]): o tamanho da empresa (em número de funcionários), a diversificação de mercados e produtos (números de países-destino e produtos exportados), além da inclusão de variáveis para controle dos setores industriais (CNAE 1.0) e unidades da federação.
} 
Tabela 2 - Empresas exportadoras após o pareamento em 2003, 2005 e 2007

\begin{tabular}{|c|c|c|c|c|c|c|c|}
\hline Ano & $\begin{array}{c}\text { Classificação das } \\
\text { Empresas } \\
\text { Exportadoras }\end{array}$ & $\begin{array}{l}\text { Número de } \\
\text { Empresas }\end{array}$ & $\begin{array}{c}\text { Exportação } \\
\text { (US\$ mil) }\end{array}$ & $\begin{array}{c}\text { Número de } \\
\text { Países para o } \\
\text { qual Exportou }\end{array}$ & $\begin{array}{c}\text { Tamanho } \\
\text { (Número de } \\
\text { Funcionários) }\end{array}$ & $\begin{array}{c}\text { Renda } \\
\text { Média } \\
(\mathrm{R} \$)\end{array}$ & $\begin{array}{l}\text { Escolaridade } \\
\text { Média (anos) }\end{array}$ \\
\hline \multirow{4}{*}{2007} & Grupo 1 & 11.010 & 7.989 & 5,8 & 249 & 1.399 & 9,33 \\
\hline & Grupo 2 & 326 & 19.105 & 14,1 & 475 & 1.347 & 9,02 \\
\hline & Grupo 3 & 326 & 19.358 & 14,4 & 473 & 1.228 & 9,27 \\
\hline & Grupo 4 & 33 & 451.531 & 56,4 & 5.896 & 2.051 & 9,56 \\
\hline \multirow{4}{*}{2005} & Grupo 1 & 10.177 & 6.681 & 5,6 & 246 & 1.250 & 8,96 \\
\hline & Grupo 2 & 397 & 12.327 & 10,5 & 421 & 1.133 & 8,54 \\
\hline & Grupo 3 & 397 & 10.794 & 12,5 & 405 & 1.093 & 8,90 \\
\hline & Grupo 4 & 55 & 255.980 & 45,0 & 3.663 & 1.638 & 9,17 \\
\hline \multirow{4}{*}{2003} & Grupo 1 & 9.811 & 3.891 & 4,7 & 199 & 1.076 & 8,58 \\
\hline & Grupo 2 & 432 & 9.321 & 10,2 & 430 & 1.100 & 8,38 \\
\hline & Grupo 3 & 432 & 8.681 & 12,3 & 489 & 1.041 & 8,52 \\
\hline & Grupo 4 & 82 & 141.589 & 40,7 & 3.099 & 1.210 & 8,46 \\
\hline
\end{tabular}

Nota: Grupo 1 - Empresas não pareadas que não receberam apoio; Grupo 2 - Empresas do grupo de Controle; Grupo 3 Empresas do grupo de Tratamento; Grupo 4 - Empresas não pareadas que receberam apoio.

Fonte: Elaboração própria com base em dados da SECEX/MDIC.

Conforme a Tabela 2, as empresas apoiadas apresentaram melhor desempenho em quase todos os quesitos listados. Além disso, as empresas exportadoras pareadas dos grupos de tratamento (grupo 3) e controle (grupo 2) apresentaram, como esperado, médias muito próximas em todas as variáveis.

$\mathrm{Na}$ segunda etapa da avaliação foi estimado um modelo de regressão utilizando dados em painel com efeitos fixos no período que se estende de 2000 a 2007. O modelo de dados em painel pode ser estimado por efeitos fixos ou por efeitos aleatórios e um método que auxilia na escolha do modelo a ser utilizado é o teste de Hausman. Nesse teste, a hipótese nula refere-se ao fato de os interceptos individuais não se correlacionarem com outros regressores. Para o caso das empresas exportadoras industriais a hipótese nula foi rejeitada, de modo que o mais indicado é a utilização do modelo de efeitos fixos, pois suas estimativas são consistentes e eficientes (Hsiao, 2002). Além disso, o modelo de efeitos fixos é a especificação apropriada se o objetivo for analisar o resultado de um conjunto de $\mathrm{N}$ empresas e a inferência se restringir ao comportamento desse conjunto (Baltagi, 2008). Portanto, os resultados a serem apresentados referem-se ao conjunto de empresas exportadoras da amostra que formaram pares.

A variável dependente é o logaritmo do valor exportado individualmente pelas empresas industriais. Assim como o valor das exportações, as demais variáveis explicativas também sofreram transformação logarítmica.

Como medida de qualificação da mão de obra, o tempo de escolaridade e a proporção de funcionários com formação superior foram utilizados como variáveis explicativas no modelo. 
Para captar a influência nos resultados em razão do tamanho das empresas foram incluídas quatro variáveis binárias (dummies) com a classificação ${ }^{7}$ de acordo com o número de funcionários das empresas.

Para mensurar a influência da diversificação de mercados e da pauta exportadora foram incluídas as variáveis quantidade de países-destino das exportações e de produtos em código NCM 8 (Nomenclatura Comum do Mercosul a oito dígitos).

Foram incluídas variáveis binárias para avaliar o impacto dos programas públicos de financiamento à exportação, de duas maneiras. A primeira procurava avaliar o impacto do acesso aos recursos públicos sobre o valor exportado no mesmo período, em $(t)$. A segunda maneira incluiu variáveis de interação entre os programas BNDES Exim e Proex e os tamanhos de empresa. A interação programa público e classe das Maiores Empresas (com mais de 500 funcionários) serviu como referência aos valores exportados pelas empresas dos demais tamanhos apoiadas pelos programas de financiamento.

Também foram incluídas variáveis binárias para cada ano do período de modo a controlar as variações que possam ter ocorridas em virtude das mudanças no ambiente econômico nesses anos.

Após a realização do pareamento, a base de dados compreendeu o período de oito anos, que se estende de 2000 a 2007 e foi composta por 3.224 empresas. Deste total, $44,3 \%$ das empresas (1.427) acessaram aos programas públicos de financiamento à exportação em pelo menos um ano.

O modelo em painel de efeitos fixos utilizado pretende controlar os efeitos das variáveis omitidas que se alteram entre os indivíduos, mas permanecem constantes ao longo do tempo. O intercepto varia de um individuo para outro, mas é constante ao longo do tempo, enquanto os parâmetros são constantes para todos os indivíduos e em todos os períodos de tempo (Gujarati, 2006).

A especificação do modelo é:

$$
\log Y_{i t}=\alpha_{i}+\log X^{\prime}{ }_{i t} \beta+\varepsilon_{i t} \quad \text { onde } i=1, \ldots N ; t=1, \ldots T
$$

Um modo de considerar o intercepto é atribuir a ele as diferenças de comportamento entre os indivíduos, ou seja, ele pode ser interpretado como o efeito das variáveis omitidas no modelo. Nesse caso, se $T \rightarrow \infty$ o estimador de efeitos fixos $\left(\alpha_{\mathrm{i}}\right)$ é

Micro e pequenas empresas com até 49 funcionários; média empresa com 50 até 249 funcionários; grande empresa com 250 a 499 funcionários e as maiores empresas com mais de 500 funcionários. Esta última é a classe de referência no modelo. 
consistente. O desafio da estimação é a presença de $N$ efeitos fixos que aumentam à medida que mais indivíduos são acrescentados à amostra. Portanto, se o $T$ é fixo e $N \rightarrow \infty$, como é típico em dados em painel, somente os estimadores $\beta$ são consistentes (Baltagi, 2008).

\subsection{PRINCIPAIS RESULTADOS}

A partir da aplicação da metodologia analisada na seção anterior, os resultados do modelo são apresentados na Tabela 3.

Tabela 3 - Resultados da regressão, modelo de dados em painel com efeitos fixos

\begin{tabular}{c|c|c|c}
\hline Variável & Coeficientes & Variável & Coeficientes \\
\hline
\end{tabular}

Valor Exportado - Variável dependente

\begin{tabular}{l|c|l|c}
\hline Micro e Pequena Empresa & $-0,7702^{* * *}$ & BNDES Exim (t) & $0,14744^{* *}$ \\
\hline Média Empresa & $-0,5236^{* * *}$ & Proex Financiamento (t) & 0,1040 NS \\
\hline Grande Empresa & $-0,0567$ NS & & $0,0884^{* * *}$ \\
\hline Escolaridade (em anos) & $0,1711^{*} \mathrm{NS}$ & País & $0,0237^{* * *}$ \\
\hline $\begin{array}{l}\text { Proporção de trabalhadores } \\
\text { com curso superior }\end{array}$ & $-0,0384$ NS & Produto (NCM 8) & $0,2855^{*}$ \\
\hline Ano 2000 & $-0,3967^{* * *}$ & BNDES Exim e MPE & $-0,0336$ NS \\
\hline Ano 2001 & $-0,5100^{* * *}$ & BNDES Exim e ME & $-0,1120$ NS \\
\hline Ano 2002 & $-0,5343^{* * *}$ & BNDES Exim e GE & $0,3405 * * *$ \\
\hline Ano 2003 & $-0,4567^{* * *}$ & Proex Financiamento e MPE & 0,1020 NS \\
\hline Ano 2004 & $-0,2255^{* * *}$ & Proex Financiamento e ME & $-0,0192$ NS \\
\hline Ano 2005 & $-0,1225^{* * *}$ & Proex Financiamento e GE & 0,5608 \\
\hline Número de observações & 5.224 & R-quadrado & \\
\hline
\end{tabular}

Nota: $\left(^{*}\right)$ significante a $\left.10 \% ;{ }^{* *}\right)$ significante a $\left.5 \% ;{ }^{* * *}\right)$ significante a $1 \%$; NS não significante. Grupo 1 - Empresas não pareadas que não receberam apoio; Grupo 2 - Empresas do grupo de Controle; Grupo 3 - Empresas do grupo. Fonte: Elaboração própria com base em dados da SECEX/MDIC.

O modelo de efeitos fixos mostrou que algumas variáveis não foram significativas estatisticamente, muito embora seu resultado tenha ocorrido de forma esperada. Por exemplo, o tempo de escolaridade apresentou influência positiva para os valores exportados pelas empresas, embora não tenha sido significativa. Por sua vez, a proporção de empregados com curso superior contrariou as expectativas e mostrou-se com influência ligeiramente negativa sobre as exportações, mas de igual modo a escolaridade não foi significativa. 
Como esperado, o valor médio das exportações das micro e pequenas empresas e das médias empresas foi menor que o valor das exportações das maiores empresas em 77,0\% e 52,4\%, respectivamente. Já o valor médio exportado pelas grandes empresas não se mostrou estatisticamente diferente das exportações médias das maiores empresas.

A inclusão de variáveis binárias para os anos do período tinha como objetivo captar alterações no ambiente econômico que influenciasse as exportações das empresas industriais. Os coeficientes mostraram que os anos de 2006 e 2007, que não se diferenciaram estatisticamente, foram os mais favoráveis às exportações das empresas da amostra. Além disso, o crescimento dos valores exportados por estas empresas se intensifica a partir de 2003-2004, quando se inicia um forte ciclo de crescimento da economia nacional que seria interrompido com a crise financeira de 2008.

O exercício econométrico revelou que o aumento da diversificação tem impactos positivos nos resultados das vendas externas. $\mathrm{O}$ acréscimo de $1 \%$ de diferentes tipos de produtos na pauta exportadora aumentou o valor exportado pela empresa em $2,4 \%$ em média, no período, enquanto que a inclusão de uma taxa de $1 \%$ de novos países aumentou as exportações em $8,8 \%$.

Dentre os programas públicos de financiamento à exportação apenas o BNDES Exim apresentou influência positiva e estatisticamente significante sobre as exportações das empresas industriais que acessaram esses recursos. Em média, o valor exportado por essas empresas foi 14,7\% superior às exportações das empresas que exportaram sem apoio público.

Outro destaque ficou por conta do bom desempenho das micro e pequenas empresas apoiadas pelo BNDES Exim. A variável de interação entre tamanho e programa de apoio mostra que essas empresas obtiveram resultado superior à média das empresas apoiadas pelo BNDES Exim. Para se obter o resultado total do impacto do programa sobre suas exportações devem ser somados o resultado dessa variável com o resultado para o total das empresas apoiadas ${ }^{8}$. Dessa forma, as micro e pequenas empresas apoiadas exportaram $43,3 \%$ a mais do que as vendas externas das micro e pequenas empresas que não contaram com o apoio do BNDES.

Para empresas de outros tamanhos, a influência positiva do BNDES Exim não se mostrou diferente estatisticamente do resultado geral obtido quando se considera todas as empresas apoiadas indiferentes ao tamanho. Ou seja, para os grupos das maiores, médias e grandes empresas da amostra o efeito do programa sobre suas exportações continuou o mesmo da amostra total $(14,7 \%)$.

\footnotetext{
8 A influência total do BNDES Exim sobre as exportações das micro e pequenas empresas é obtida pela soma do coeficiente geral do programa de financiamento $(0,1474)$ e do coeficiente relativo às micro e pequenas empresas (quando $\mathrm{MPE}=1$ o coeficiente é de 0,2855 ). Dessa forma, as empresas MPE exportaram 43,3\% a mais do que as MPE que não contaram com o apoio do BNDES Exim.
} 
Com relação ao Proex Financiamento, apesar de o coeficiente ser positivo, as exportações das empresas apoiadas por esse programa não se mostraram diferentes estatisticamente das empresas que exportaram sem acessar os recursos da linha do Banco do Brasil. Apesar de o resultado para o Proex no geral ter sido não significativo, o resultado das empresas de menor porte foi significativo estatisticamente. Portanto, as micro e pequenas empresas que contrataram esse programa apresentaram melhor desempenho em relação às empresas do mesmo porte não apoiadas. Esse tipo de empresa quando apoiada exportou, em média, 34,1\% a mais do que as empresas da mesma classe de tamanho que não acessaram ao Proex Financiamento.

Os resultados encontrados para as empresas de menor porte em ambos os programas públicos chamam a atenção para a existência de um conjunto de empresas exportadoras competitivas, apesar do tamanho reduzido. Pesquisas posteriores são necessárias para a realização de um mapeamento mais detalhado dessas empresas e suas características.

Portanto, o BNDES Exim apresentou impactos positivos sobre os valores exportados pelas empresas industriais. Esse impacto é ainda maior para as micro e pequenas empresas que conseguiram obter o apoio do programa. Em termos gerais, os resultados do Proex Financiamento não se mostraram significativos para o total da amostra das empresas apoiadas, mas indicaram que esse programa foi muito importante para as empresas de menor porte.

\section{CONCLUSÃO}

As exportações possuem um papel estratégico como um mecanismo de desenvolvimento econômico. Apesar do crescimento verificado nos últimos anos nas exportações brasileiras, chama atenção também a perda de importância relativa dos produtos manufaturados na pauta brasileira, em especial dos produtos mais intensivos em tecnologia e conhecimento. Nesse contexto, as políticas de apoio à exportação ganham importância, tanto para sustentar o crescimento das exportações, como para apoiar a maior participação dos produtos de maior intensidade tecnológica e geração de valor na pauta.

Os programas públicos de financiamento à exportação assumem papel importante dentro dessa estratégia, ao assumirem funções complementares aos mecanismos privados de financiamento, seja para atingir as micro e pequenas empresas, seja para a concessão com prazos maiores para empresas que possuem ciclo de desenvolvimento/ produção e comercialização mais longos, ou ainda para direcionamento dos recursos aos setores mais intensivos em tecnologia e conhecimento. 
Com o objetivo de realizar uma avaliação dos programas públicos de financiamento à exportação, calculou-se um índice de intensidade de apoio aos setores exportadores para avaliar a especialização do apoio do BNDES Exim e do Proex Financiamento. Os resultados analisados neste trabalho mostram que BNDES Exim apoiou mais intensamente os setores de maior geração de valor, maior intensidade tecnológica e menor participação na pauta exportadora nacional. O Proex Financiamento, por sua vez, concentrou seus desembolsos em setores tradicionais, com predominância de empresas de pequeno porte, menos intensivos em tecnologia e que reforçam a especialização brasileira no comércio exterior. Portanto, a despeito de certa complementaridade entre esses programas no que diz respeito ao tamanho das empresas apoiadas, o impacto do BNDES Exim foi maior no sentido de alterar a composição da pauta exportadora nacional em direção a produtos mais intensivos em tecnologia.

Com relação à mensuração dos impactos que os programas públicos do BNDES e do Banco do Brasil exercem sobre os valores exportados pelas empresas industriais, foi adotado um método (matching) que possibilitou a formação de dois grupos de empresas similares em quase todos os aspectos, com exceção ao acesso aos recursos públicos. A amostra formada após o pareamento com os grupos de empresas que acessaram os recursos públicos e as que não acessaram foi submetida a um modelo de regressão com dados em painel com efeitos fixos.

Os resultados mostraram influência positiva BNDES Exim sobre as exportações das empresas industriais. As empresas apoiadas por esse programa exportaram, em média, $14,7 \%$ a mais do que as empresas similares que não receberam apoio do programa. Para o grupo de micro e pequenas empresas apoiadas o programa mostrou-se ainda mais importante. As exportações dessas empresas superaram em 43,3\% os valores exportados pelas empresas da mesma classe de tamanho que não obtiveram financiamento.

O Proex Financiamento não apresentou resultado estatisticamente significativo no total das empresas apoiadas no período, porém, mostrou-se importante para as exportações das micro e pequenas empresas. Controlando para o tamanho das empresas, as de menor porte que acessaram recursos do programa exportaram 34,1\% a mais, em média, do que empresas do mesmo porte que não receberam apoio.

Portanto, pode-se concluir que os programas públicos de financiamento às exportações brasileiras, em especial o do BNDES, possuem impactos positivos sobre os valores exportados pelas empresas industriais, mas algumas correções têm de ser feitas para melhorar a eficácia desses programas e para que eles possam entregar melhores resultados. Por exemplo, a contribuição do Proex se mostrou relevante às empresas menores e não resultou significativo para os demais tamanhos de empresas. Isso pode indicar que a eficiência aumentaria se esse programa se dedicasse ao financiamento 
apenas desse tipo de empresas. Para que correções de rota nas políticas públicas sejam possíveis, é de fundamental importância os exercícios que busquem avaliar continuamente os resultados dessas políticas, objetivo para o qual este trabalho procurou contribuir.

\section{REFERÊNCIAS}

ARAÚJO, B. C. P. O. Potencial das firmas industriais brasileiras e a dimensão tecnológica. In: DE NEGRI, J. A.; ARAÚJO, B. (Orgs.) As empresas brasileiras e o comércio internacional. Brasília: IPEA, 2006, p. 57-86.

BALTAGI, B. H. Econometric analysis of panel data. 4. ed. New York: Wiley, 2008.

BLUMENSCHEIN, F.; DE LEON, F. L. L. "Uma análise de desempenho e da segmentação do sistema de crédito à exportação no Brasil”. In: PINHEIRO A.C., MARKWALD, R.; PEREIRA, L. V. (Orgs.) O desafio das exportações. Rio de Janeiro: BNDES, 2002, p. 175-243.

CAMERON, A. C.; TRIVEDI, P. K. Microeconometrics: methods and applications. New York: Cambridge University Press, 2005.

CATERMOL, F. BNDES-Exim: 15 anos de apoio às exportações brasileiras. Revista do BNDES, Rio de Janeiro, v. 12, n. 24, p. 3-30, dez. 2005.

CENTRO DE ESTUDOS DE CONJUNTURA E POLÍTICA ECONÔMICAS (CECON). Perspectivas da indústria financeira brasileira e o papel dos bancos públicos. [on-line] 2009. Disponível em: <http://www.iececon.net/pesquisa.htm>. Acesso em: 15 abr. 2010.

DE NEGRI, F; VASCONCELOS L. F.; GALETTI, J. Abrangência das políticas de apoio às exportações no Brasil e perfil das empresas beneficiadas. Radar IPEA, Tecnologia, Produção e Comércio Exterior, n. 11, dez. 2010. Disponível em: <http://www.ipea.gov.br/portal/images/stories/PDFs/radar/101216_radar11.pdf>. Acesso em: 16 dez. 2013.

GUJARATI, D. Econometria Básica. 4. ed. São Paulo: Makron Books, 2006.

HSIAO, C. Analysis of panel data. New York: Cambridge University Press, 2002.

MARKWALD, R.; PUGA, F. P. “Focando a política de promoção de exportações”. In: PINHEIRO A.C., MARKWALD, R.; PEREIRA, L. V. (Orgs.) O desafio das exportações. Rio de Janeiro: BNDES, 2002, p. 97-154.

MOREIRA, H. C.; PANARIELLO, M. Os incentivos à exportação brasileira: 1990 a 2004. Documentos IPEA/CEPAL. Texto para Discussão, IPEA, n. 1385, 2009.

MOREIRA, S. V.; SANTOS, A. F. Políticas públicas de exportação: o caso do Proex. Texto para Discussão, IPEA, n. 836, 2001.

MOREIRA, S. V.; TOMICH, F.; RODRIGUES, M. G. Proex e BNDES-Exim: construindo o futuro. Texto para Discussão, IPEA, n. 1156, 2006.

PEREIRA, T. R., MACIENTE; A. Impactos dos mecanismos de financiamento (ACC e ACE) sobre a rentabilidade das exportações brasileiras. Texto para Discussão, IPEA, n. 722, 2000. 
PIANTO, D. M.; CHANG, L. "O potencial exportador e as políticas de promoção das exportações da APEX-Brasil”. In: DE NEGRI, J. A.; ARAÚJO, B. (Orgs.) As empresas brasileiras e o comércio internacional. Brasília: IPEA, 2006, p. 87-108.

RHEE, Y. W. Trade finance in developing economies. Policy \& Research, World Bank, n. 5, 1989.

ROSENBAUM, P. R.; RUBIN D. B. The central role of the propensity score in observational studies for causal effects. Biometrika, v. 70, n. 1, p. 41-55, 1983.

SERINGHAUS, F. H. R.; ROSSON P. J. Government export promotion: a global perspective. New York: Routledge, 1990.

VEIGA, P. M.; IGLESIAS, R. M. A política de financiamento à exportação no Brasil. Aspectos estratégicos da política comercial brasileira. Rio de Janeiro: REDIPEA/BID, 2000. 